\title{
Investigation of the Pipe Weld for Brittle Metal Fracture
}

\author{
V.B. Kulnevich ${ }^{1}$ and E.V. Mal'kova ${ }^{1, *}$ \\ ${ }^{1}$ South Ural State Agrarian University, 454080, Chelyabinsk, Russia
}

\begin{abstract}
The article presents the results of studies of artificial strain aging of pipe steels. The effect of deformation aging on the mechanical properties of steel during tensile tests has been determined.
\end{abstract}

\section{Relevance of the research}

Natural aging of a metal is a long-term process and the selection of an analogue of such aging that allows it to be simulated in a short time is important. This is especially true for pipelines and other elements that transport oil and gas products and are in operation for a long time, since the aged metal cannot withstand the loads and collapse [1,2].

There is aging of the metal, which manifests itself in a change in its properties after a certain period of time at normal or elevated temperatures, as well as strain aging in which the metal changes its properties (embrittles) after plastic deformation at temperatures below the recrystallization temperature [3]. Both types of aging lead to a decrease in the ductility of steel and to a decrease in the bearing capacity, in particular of welded joints.

Aging processes occurring in welded joints during long-term operation have similar deformation mechanisms and deformation aging fracture morphology reproduced in laboratory conditions.

Knowledge of the effect of artificial aging on the mechanical properties of the metal of welded structures allows one to estimate, in a first approximation, their mechanical behavior under natural aging conditions with long service life, the bearing capacity of welded joints, and to regulate the operational parameters of the structures in order to exclude their brittle damages [4].

The main factors contributing to the deformation (mechanical) aging of the metal are preliminary cold plastic deformation, heating temperature and time of structural and deformation processes associated with the distribution of cementite, redistribution of impurity atoms, accumulation of irreversible microdeformations, formation and decomposition of carbide and nitride particles, etc. [5]. It is known that preliminary cold deformation, sometimes even with small degrees, and deformation aging reduce the ductility and toughness of steels and, with an appropriate choice of deformation aging modes, make it possible to obtain a change in the nature of fracture from ductile to brittle $[3,6,7]$.

For critical welded structures, such as main pipelines, the issues under consideration are especially relevant due to the fact that the technology of manufacturing and repairing pipes and pipelines is accompanied by cold plastic deformation (molding, expansion, installation),

*Corresponding author: vetochka.79@mail.ru 
temperature effects (cutting, welding, insulation) and, in addition, pipelines have been in operation for a long time.

\section{Research object}

In order to establish the temperature-deformation dependence and the zone of transition from ductile fracture to brittle fracture, the weld metal of the welded joint made of steel $17 \mathrm{G} 1 \mathrm{~S}$ with a thickness of $13 \mathrm{~mm}$ was investigated. Welding was carried out with stick electrodes of the UONI 13/55 brand, type E50A. Single samples were used to assess the degree of strain aging.

The sample is a narrow plate (closer to the square), in the middle of which a cylindrical groove is made. This design of the specimen allows localizing deformations in the working part of the specimen and setting a sufficiently large degree of preliminary deformation by compression without destroying the specimen. The sample was grooved along the weld metal. The elongated non-working part of the sample is necessary for its reliable grip in the jaws of the testing machine under tension. All samples were cut from the plates across the weld, using abrasive wheels and water cooling to exclude heating of the metal and structural changes in it.

The investigated weld metal has a chemical composition shown in Table 1.

Table 1. Chemical composition of the weld metal under study, $\%$

\begin{tabular}{|c|c|c|c|c|}
\hline $\mathrm{C}$ & $\mathrm{Mn}$ & $\mathrm{Si}$ & $\mathrm{S}$ & $\mathrm{P}$ \\
\hline $0,09 \ldots 0,11$ & $0,80 \ldots 0,90$ & $0,35 \ldots 0,45$ & $\leq 0,03$ & $\leq 0,03$ \\
\hline
\end{tabular}

\section{Theoretical justification of the research}

The most important factors that reduce the ductility of steel are plastic deformation and temperature. During the tests, the samples were subjected to cold plastic deformation by compression in the range of $0 \ldots 80 \%$. The preliminary deformation was created by cold compression in a special container, which provided the conditions of axisymmetric deformation in the working part of the specimen. To obtain large plastic deformations (more than $30 \ldots 40 \%$ ), loading was carried out in several stages, followed by machining, restoring the original working section of the sample. The amount of preliminary deformation was determined according to the following dependency [7]:

$$
\varepsilon_{p r}=\frac{F-F_{0}}{F_{0}} \cdot 100 \%=\frac{d^{2}-d_{0}^{2}}{d_{0}^{2}} \cdot 100 \%,
$$

where $d_{0}, F_{0}$ - initial diameter and cross-sectional area of the sample bore; $d, \mathbf{F}$ - diameter and crosssectional area of the sample groove after preliminary compression.

After plastic deformation, the samples were heat treated in a shaft furnace for 1 hour 30 min, followed by cooling in air. The batches of samples were heated within the temperature range from $150^{\circ} \mathrm{C}$ to $600^{\circ} \mathrm{C}$ with an interval of $50^{\circ} \mathrm{C}$. After preliminary deformation and heat treatment, the working part (weld metal) was machined to the initial diameter.

The mechanical properties of the aged metal were determined by static tensile tests. The chosen shape of the specimen made it possible to localize the plastic flow and fracture of the specimen in that part of it that was exposed to temperature and deformation and, thereby, determine the mechanical characteristics of the metal after strain aging.

The strength and plastic properties were evaluated by the value of the ultimate tensile strength $\left(\sigma_{t}\right)$ and the relative narrowing of the cross section $(\psi)$, the value of which was used 
to determine the nature of destruction of the sample (ductile or brittle). Evaluation of the plastic properties of the metal by $\psi$ is more preferable, since the relative narrowing is a more sensitive characteristic of plasticity, independent of the deformation base. According to the test results, graphs of the dependence of the relative narrowing $\psi$ on the parameters of artificial aging $\varepsilon_{p r}$ and $T$ were plotted (Fig. 1).

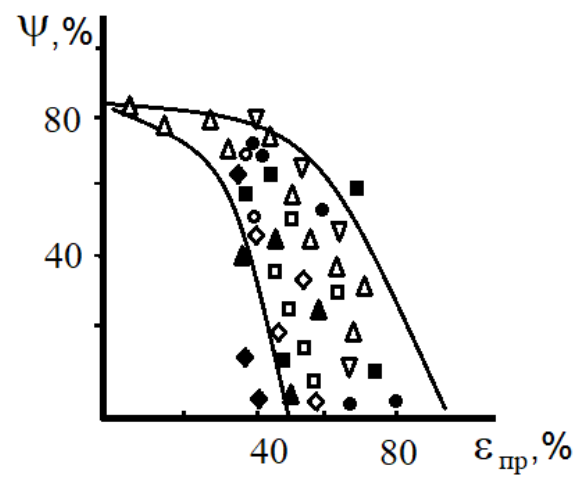

Fig. 1. Dependency of the relative narrowing $\psi$ on the parameters of artificial aging $\varepsilon_{\mathrm{pr}}: \mathbf{0}-150^{\circ} \mathrm{C}$;

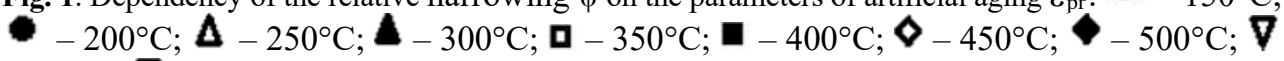
$-550^{\circ} \mathrm{C} ;-600^{\circ} \mathrm{C}$.

Mechanical tests revealed a decrease in the plastic properties of the metal depending on the parameters of strain aging up to the change in the nature of fracture from ductile to brittle. Based on the test results, the dependence of the nature of destruction on the magnitude of the preliminary deformation and the temperature of the subsequent heat treatment, the so-called C-shaped curve, was plotted (Fig. 2). This curve shows that stable embrittlement of the weld metal is achieved with preliminary deformation by compression not lower than $40 \ldots 50 \%$ and the temperature of heat treatment of deformed samples in the range of $300 \ldots 400^{\circ} \mathrm{C}$. It is noticed that with an increase in the temperature of heat treatment, the ultimate resistance $\left(\sigma_{t}\right)$ slightly increases and then decreases. The relative narrowing has an inverse relationship.

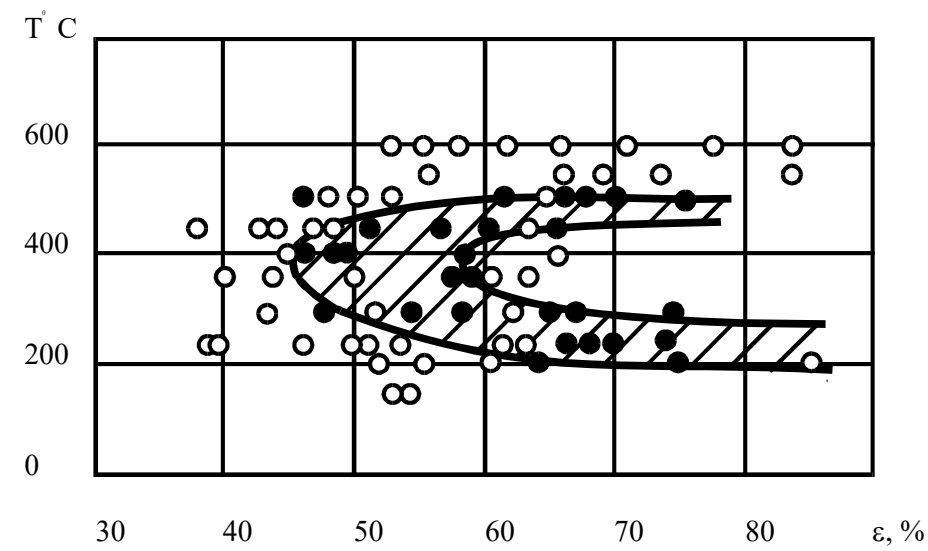

Fig. 2. Dependency of the nature of destruction on the magnitude of the preliminary deformation and the temperature of subsequent processing: $\mathbf{O}$-ductile fracture; - brittle destruction 


\section{Conclusion}

It can be seen from the test results that embrittlement is stably achieved jointly by preliminary deformation and subsequent heat treatment, while for each heat treatment temperature there is a critical degree of preliminary deformation, when exceeding which the steel fails brittle during testing. Stable embrittlement of the weld metal is achieved with preliminary deformation by compression not lower than $45 \ldots 60 \%$ and the temperature of heat treatment of the samples in the range of $200 \ldots 500^{\circ} \mathrm{C}$.

Preliminary deformation of specimens by compression, with the exception of specimens with large plastic deformation and heat treatment in the range of $300 \ldots 450^{\circ} \mathrm{C}$, has no significant effect on the change in strength indicators.

\section{References}

1. Nokhrin A.V., Chuvildeev V.N. Aging of steel pipes for main gas pipelines. Bulletin of the Nizhny Novgorod University. N.I. Lobachevsky. 2010. No. 5 (2). P. 171-180.

2. Prediction of the residual life of the strength of main gas and oil pipelines taking into account the duration of operation / Yu.I. Pashkov, Yu.I. Anisimov, V.B. Kulnevich and A.I. Lanchakov, A.I. Stepanenko, V.V. Ershov. Construction of pipelines. 1996. No. 2. P. 2-5.

3. Polyanskaya I.L., Filisyuk N.V. Investigation of the effect of the duration of artificial aging on the properties of steel. Scientific notes of the Komsomolsk-on-Amur State Technical University. 2016. Volume 1. No. 4. P. 86-96.

4. Yamaleev K.M. Aging of pipe metal during the operation of oil pipelines. Transportation and storage of petroleum products. 1990.Vol. 64.P. 64.

5. Deformation aging in steels / V.M. Farber, O.V. Selivanova, V.A. Khotinov, O.N. Polukhina. - Yekaterinburg: Ural Publishing House. University, 2018 .-- 72 p.

6. Investigation of the mechanism of change in the structural state in the process of deformation aging and its influence on the properties of bainitic-type pipe steel. Mishetyan, I.P. Shabalov, O.N. Chevskaya, G.A. Filippov. Ferrous metallurgy. Bulletin of scientific, technical and economic information. 2018. No. 9. P. 77-92.

7. Babich V.K., Gul' Yu.P. Deformation aging of steel. Moscow: Metallurgy, 1972. 320 p. 